\title{
Afatinib treatment in advanced non-small cell lung cancer
}

\author{
This article was published in the following Dove Press journal: \\ Lung Cancer:Targets and Therapy \\ 6 October 2011 \\ Number of times this article has been viewed
}

\section{Jane L Hurwitz \\ Paula Scullin \\ Lynn Campbell}

Department of Medical Oncology, Northern Ireland Cancer Centre, Belfast, UK
Correspondence: Lynn Campbell, Northern Ireland Cancer Centre, 97 Lisburn Road, Belfast BT9 7AB, UK

Tel +44 28 9032924I

Email lynn.campbell@belfasttrust.hscni. net
Abstract: Despite some recent advances in the management of advanced non-small cell lung cancer (NSCLC), prognosis for these patients remains poor. Small molecule epidermal growth factor receptor (EGFR) tyrosine kinase inhibitors (TKIs) have however provided a new therapeutic option in this disease setting and EGFR mutation testing is now routine practice for newly diagnosed NSCLC patients. A proportion of patients will not respond to first-generation EGFR-TKIs however, and those who do will ultimately develop resistance and disease relapse. Next-generation EGFR-TKIs which inhibit multiple members of the EGFR family are being developed in order to increase sensitivity and overcome resistance to existing agents. Afatinib (BIBW 2992) is an oral, irreversible inhibitor of EGFR and HER2 tyrosine kinases and is the most advanced of these agents in clinical development. Pre-clinical and early-phase clinical trials have demonstrated a favorable safety profile as a single agent and in combination with other anti-cancer agents, and provide evidence of clinical activity in advanced NSCLC. The LUX-Lung trials suggest that for selected patients, afatinib offers symptomatic improvement and prolonged progression-free survival, although this has not yet translated into improved overall survival. This article aims to review the use of EGFR-TKIs in the management of advanced NSCLC and the mechanisms underlying resistance to these agents. We will discuss the current pre-clinical and clinical data regarding afatinib, its potential to overcome resistance to firstgeneration TKIs, and its emerging role in advanced NSCLC treatment.

Keywords: EGFR, tyrosine kinase inhibitor, mutation, LUX-Lung

\section{Introduction}

Lung cancer is the most common cancer in the world. In the UK, there are around 40,000 new cases annually, and it is the leading cause of cancer-related death. Non-small cell lung cancer (NSCLC) accounts for 80\%-85\% of all lung cancer cases. The majority of patients present with advanced/metastatic (Stage IIIB or IV) disease and are therefore not suitable for radical/curative treatment. Treatment for this group is aimed at palliating symptoms, controlling disease, and prolonging survival. For many years, cytotoxic chemotherapy was the mainstay of treatment for advanced NSCLC and despite more recent advances allowing individualization of treatment based on histological differentiation, prognosis for these patients remains poor with a median overall survival (OS) of 8-10 months. The introduction of small molecule epidermal growth factor receptor (EGFR) tyrosine kinase inhibitors (TKIs) has however provided a new therapeutic option in this disease setting and EGFR mutation testing represents a unique development in terms of molecular biomarkers of drug sensitivity. Resistance to first-generation EGFR-TKIs is common and therefore new 
strategies are necessary to combat this. The development of next-generation EGFR-TKIs such as afatinib, which target multiple members of the EGFR family, is one such strategy. This article aims to review the current data regarding the use of afatinib, and discuss its potential role in the treatment of advanced NSCLC.

\section{Current management of advanced NSCLC First-line treatment}

In the first-line setting, chemotherapy with platinum in combination with a third-generation agent (paclitaxel, gemcitabine, vinorelbine) remains the standard of care for the majority of patients and offers a modest survival benefit compared to best supportive care (BSC). ${ }^{1-4}$ Recently an additional survival advantage for pemetrexed-cisplatin chemotherapy in non-squamous NSCLC was confirmed. ${ }^{5}$ Additionally, several targeted agents have now also been demonstrated to increase efficacy in first-line NSCLC treatment when added to a platinum doublet. Bevacizumab (Avastin ${ }^{\circledR}$, Roche, Basel, Switzerland), an anti-vascular endothelial growth factor (VEGF) monoclonal antibody, in combination with carboplatinpaclitaxel demonstrated significant improvements in median OS (12.3 months vs 10.3 months; HR: 0.79; $P=0.003)$, progression free survival (PFS) (6.2 months vs 4.5 months; HR: $0.66 ; P<0.001)$, and response rates (RRs) $(35 \%$ vs $15 \% ; P<0.001)$ compared to chemotherapy alone. ${ }^{6}$ This was most marked in patients with adenocarcinomas and has been approved by the FDA for first-line treatment of advanced non-squamous NSCLC. The Phase III First-Line Treatment for Patients with EGFR-EXpressing Advanced NSCLC (FLEX) trial evaluated cetuximab (Erbitux ${ }^{\circledR}$, Bristol-Myers Squibb, Moreton, UK), a monoclonal antibody to EGFR, in combination with cisplatin-vinorelbine. ${ }^{7}$ Cetuximab demonstrated superior RRs (36.6\% vs 29\%) and median OS (11.3 vs 10.1 months; HR: $0.79,95 \%$ CI: $0.762-0.996$; $P=0.044)$ compared to chemotherapy alone. The European Medicines Agency (EMA) however have not yet extended cetuximab's license to cover NSCLC.

Sequential or maintenance therapy, post-first-line treatment for NSCLC patients who have not experienced disease progression, has also been investigated. Pemetrexed is the only agent that has been shown to significantly improve both PFS and OS as maintenance therapy, and in keeping with other studies using this agent, this was most apparent in patients with non-squamous histology. ${ }^{8}$

The above studies highlight the importance of histological sub-typing in the management of advanced NSCLC. Recently however the introduction of EGFR mutation testing has provided a major step forward as a novel predictive marker of likely response to treatment and has allowed further individualization of therapy.

The EGFR and its associated tyrosine kinase signaling pathway are implicated in a range of malignancies, including NSCLC. The pathway is involved in carcinogenesis as a result of protein over-expression, gene amplification, or genetic mutations and has emerged as a leading target for NSCLC therapy. ${ }^{9}$ Erlotinib (Tarceva ${ }^{\circledR}$, OSI Pharmaceuticals, Ardsley, NY) and gefitinib (Iressa ${ }^{\mathrm{TM}}$, Astra Zeneca Inc, London, UK) were developed as small molecule reversible EGFR-TKIs which act by competing with ATP at the intracellular catalytic domain of EGFR to prevent binding. This prevents receptor phosphorylation and subsequently inhibits downstream intracellular signaling. Subgroup analyses from the initial clinical trials of these agents showed that patients with certain clinical and histological characteristics (women, patients of East Asian descent, non-smokers, those with adenocarcinomas, and those with specific activating mutations of EGFR) who received erlotinib or gefitinib had higher rates of response and survival.

The Phase III IPASS study, which was conducted in Asia, randomized chemotherapy-naïve patients with adenocarcinoma and who were non-smokers or ex-light-smokers to receive gefitinib or carboplatin-paclitaxel as first-line treatment. ${ }^{10}$ This study reported an improved PFS at 1 year in the gefitinib group (29.7\% vs $6.7 \%)$, and this was most pronounced in those patients harboring an activating $E G F R$ mutation (HR: 0.48 , 95\% CI: $0.36-0.64 ; P<0.001$ ). In contrast, patients without an EGFR mutation had worse outcomes when treated with gefitinib compared to chemotherapy. In July 2010, gefitinib was approved by NICE as a first-line treatment option for patients with locally advanced or metastatic NSCLC with EGFR-TK mutation. The smaller NEJGSG, First-SIGNAL, and WJTOG3405 trials support the IPASS data, showing significant improvements in PFS for gefitinib compared to chemotherapy in patients with EGFR mutations. ${ }^{11-13}$ In the OPTIMAL trial, chemo-naïve patients with advanced NSCLC with an activating EGFR mutation were randomized to receive erlotinib or carboplatingemcitabine. PFS was significantly improved in the erlotinib group although OS data is not available at present. ${ }^{14}$

\section{Second-line treatment}

Unfortunately the majority of patients with advanced NSCLC relapse or become refractory to first-line treatment. If performance status allows, they can be considered for second-line 
therapy. In this setting, docetaxel produced a RR of $7.1 \%$, (with a further $43 \%$ achieving stable disease [SD]) and significant improvements in time to progression (TTP) (10.6 vs 6.7 weeks; $P<0.001)$ and OS (7.0 vs 4.6 months; $P=0.047)$ in those patients receiving docetaxel plus BSC compared to BSC alone. ${ }^{15}$ Docetaxel has been subsequently compared to pemetrexed in patients previously treated with platinum-based chemotherapy, however there were no significant differences in RR, PFS, or OS between the two groups. ${ }^{16}$

Following the BR21 trial comparing erlotinib to BSC, erlotinib has also been licensed for the second-line treatment of NSCLC. Despite the modest RR of 9\% (with SD in a further $38 \%$ ), patients receiving erlotinib demonstrated a significantly improved OS (6.7 vs 4.7 months; HR: 0.70; $P<0.001)$, PFS (2.2 vs 1.8 months; $P<0.001$ ), and QOL compared to $\mathrm{BSC}^{17}$

The ISEL trial compared gefitinib to placebo and demonstrated a prolonged TTP (3.0 vs 2.6 months; $P<0.001$ ) but not OS in NSCLC patients who had previously been treated with standard chemotherapy. ${ }^{18}$ Subsequently, the INTEREST trial which recruited patients with relapsed disease reported that gefitinib was not inferior in terms of OS compared to docetaxel, however is not currently licensed in this setting. ${ }^{19}$ $E G F R$ mutation positive patients previously treated with gefitinib in the first-line setting would now typically receive a platinum-based doublet upon relapse.

\section{Third-line treatment}

No FDA (Food and Drug Administration) or NICE (National Institute for Health and Clinical Excellence) approved thirdline treatment options exist and the evidence for clear clinical benefit in this setting is lacking at present. Few NSCLC patients who have relapsed after second-line treatment are of suitable performance status to consider further cytotoxic chemotherapy. The oral bioavailability and more favorable toxicity profile of targeted agents like EGFR-TKIs may represent a more promising strategy, however both the ISEL and BR21 trials included a small proportion of such patients and minimal clinical benefit was demonstrated.

\section{Afatinib in the treatment of advanced NSCLC EGFR mutation testing and resistance to first-generation EGFR-TKIs}

As described above, the first-generation EGFR-TKIs have been incorporated into the treatment of advanced NSCLC and have been shown to be most effective in those patients with an activating mutation in the kinase domain of EGFR. In-frame deletions at exon 19 that eliminate four amino acids (del19, 746-753, ELREA) and a missense mutation at exon 21 resulting in the substitution of arginine for leucine at position 858 (L858R $)^{20,21}$ have been identified as the most common mutations $(80 \%-85 \%)$ and are estimated to occur in $10 \%-40 \%$ of NSCLC patients worldwide. ${ }^{22}$ Variations in frequency of EGFR mutations are apparent between different ethnic groups (Caucasians $\sim 15 \%$, Asians $\sim 35 \%-40 \%$ ). Screening for these mutations in patients newly diagnosed with NSCLC is now routine practice in most centers, thus allowing treatment decisions based on individual phenotype.

Although response rates to first-generation TKIs are relatively higher in patients with these activating mutations, $20 \%-30 \%$ of patients will not respond to these agents, thus displaying primary or innate resistance. ${ }^{10,12,14,22}$ It has been suggested that activating KRAS mutations (which occur most frequently in codon 12 and 13 of exon 2 and are present in $15 \%-25 \%$ of lung adenocarcinomas $)^{23}$ may be implicated in primary resistance to erlotinib and gefitinib. ${ }^{24}$ In a biomarker analysis from the BR21 trial, patients whose tumors had wildtype $K R A S$ had a survival advantage with erlotinib compared to placebo (HR: $0.69,95 \% \mathrm{CI}: 0.49-0.97 ; P=0.03$ ) whereas those with mutant $K R A S$ did not (HR: 1.67, 95\% CI: 0.62-4.5; $P=0.31) .{ }^{25}$ Upregulation of the VEGF and IGF-1 (insulin-like growth factor-1) signaling pathways have also been associated with EGFR-TKI resistance in pre-clinical studies. ${ }^{26}$

Those patients initially responding to EGFR-TKIs will typically develop resistance leading to relapse of disease (median duration of response 14 months). ${ }^{27}$ This is termed secondary or acquired resistance. Mutations in exon 20 of the EGFR kinase domain account for a significant proportion of these cases. Specifically, the T790M mutation (a substitution of methionine for threonine at position 790), is a common cause of acquired resistance and has been found in approximately $50 \%$ of patients who have relapsed after an initial response to first-generation EGFR-TKIs. ${ }^{26,28,29}$ This mutation has also been linked to primary resistance. MET (mesenchymal-epithelial transition factor) amplification is another possible mechanism causing EGFR-TKI resistance. In the study by Bean et al $M E T$ amplification was reported to be more common in EGFR mutant tumors of patients who have developed resistance to erlotinib or gefitinib compared to untreated patients $(21 \%$ vs $3 \% ; P=0.007) .{ }^{30}$ In a second study, MET amplification was seen in $22 \%$ of patients who had acquired resistance to gefitinib or erlotinib and in a gefitinib-sensitive cell line with acquired resistance. ${ }^{31}$ Figure 1 summarizes resistance mechanisms to first-generation TKIs. 


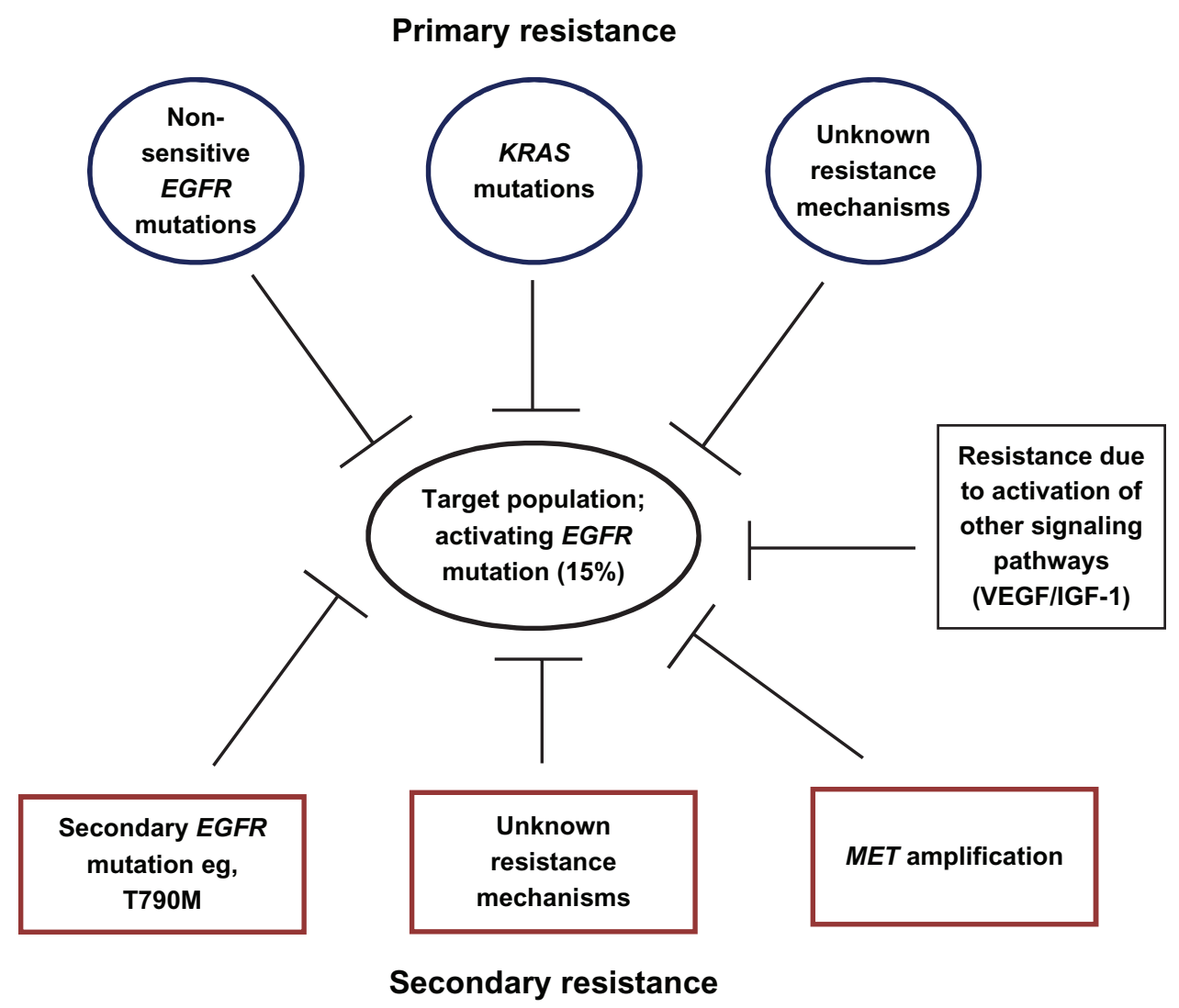

Figure I Summary of mechanisms underlying resistance to first-generation EGFR-TKIs.

To overcome resistance and improve on the modest survival benefit conferred by erlotinib and gefitinib, second-generation TKIs are being developed. These include agents which can form irreversible covalent bonds to the EGFR TK domain (in contrast to first-generation TKIs which act via competitive binding with ATP to produce reversible inhibition), therefore theoretically prolonging inhibition of signaling. Many of the new agents are also designed to block multiple EGFR family members, resulting in inhibition of parallel signaling pathways which may be implicated in resistance. EKB-569 is an irreversible EGFR inhibitor which has been investigated in a Phase II study in NSCLC. ${ }^{32}$ HKI-272 is another irreversible inhibitor targeting EGFR and HER2 and CI-1033 is a pan-HER inhibitor (blocking EGFR, HER2, and HER4). Both agents have been evaluated in Phase II trials in advanced NSCLC but demonstrated minimal efficacy. ${ }^{33,34}$ PF-00299804 also irreversibly inhibits EGFR, HER2, and HER4 and has shown moderate activity in advanced NSCLC. ${ }^{35}$ Afatinib (BIBW 2992, Tomtovok ${ }^{\mathrm{TM}}$, previously Tovok ${ }^{\mathrm{TM}}$, Boehringer Ingelheim, Ingelheim, Germany), an irreversible inhibitor of both EGFR and HER2 is the most advanced of the second-generation TKIs in clinical development and pre-clinical and clinical studies have confirmed activity in advanced NSCLC.

\section{Pharmacology and pharmacokinetics of afatinib (BIBW 2992)}

Afatinib, an anilino-quinazoline derivative, is a highly selective, potent, and irreversible inhibitor of both EGFR $\left(\mathrm{IC}_{50} 0.5 \mathrm{nM}\right)$ and HER2 $\left(\mathrm{IC}_{50} 14 \mathrm{nM}\right)$ tyrosine kinases. ${ }^{36}$ The chemical structure of afatinib is shown in Figure 2. It has been shown to inhibit EGFR and HER2 phosphorylation and subsequent kinase activity in vitro, in both EGFR mutants resistant to firstgeneration TKIs and wild-type EGFR and HER2 cell lines. Increased cell death in NSCLC cell lines and tumor regression<smiles>CN(C)C/C=C/C(=O)Nc1cc2c(Nc3ccc(F)c(Cl)c3)ncnc2cc1O[C@H]1CCOC1</smiles>

Figure 2 Chemical structure of BIBW 2992 (afatinib). 
in mouse xenograft models has also been demonstrated at lower concentrations than erlotinib or gefitinib. ${ }^{37,38}$ Of note, afatinib has been demonstrated to exhibit in vivo and in vitro activity in the presence of the L858R/T790M double mutation, which models the acquisition of resistance in patients with NSCLC previously responding to TKIs. ${ }^{37}$

A healthy volunteer study primarily examined the safety and pharmacology of $\left[{ }^{14} \mathrm{C}\right]$-radiolabelled BIBW 2992. This Phase I open-label, single-dose study recruited eight healthy males. Each received a single dose of BIBW 2992 containing 2.25 MBq of $\left[{ }^{14} \mathrm{C}\right]$-radiolabeled BIBW $2992 .{ }^{39}$ This was well tolerated. Maximum mean plasma concentration $\left(\mathrm{C}_{\text {max }}\right)$ was recorded at 6 hours post-dose and terminal half-life $\left(\mathrm{t}_{1 / 2}\right)$ at 33.9 hours. The major route of elimination of BIBW 2992 was via the feces and a relatively high apparent total body clearance was determined. These data also suggest the presence of one or more metabolites of BIBW 2992 in plasma and in whole blood with a longer $t_{1 / 2}$ than BIBW 2992.

In the dose-escalation Phase I studies, patients with advanced solid tumors expressing EGFR and/or HER2 received oral afatinib according to a variety of dosing schedules. ${ }^{36,40-42}$ Pharmacokinetic (PK) evaluation revealed oral bioavailability and moderately fast absorption with $\mathrm{t}_{\max }$ occurring 1-4 hours post dose. ${ }^{36}$ Drug absorption was however reduced after food intake, suggesting that afatinib is best administered under fasting conditions.

$\mathrm{C}_{\max }$ and exposure increased linearly with dose. Steady state was generally achieved following 7-8 days of continuous dosing. ${ }^{36,41}$ All PK parameters displayed moderateto-high variability within the expected range for orally administered EGFR-TKIs. $\mathrm{t}_{1 / 2}$ fell between $21-43$ hours, therefore making afatinib suitable for once-daily dosing. Furthermore, drug clearance parameters were not clearly associated with weight and surface area, thus supporting fixed drug dose administration.

\section{Phase I clinical studies}

Initial Phase I studies determined the safety of BIBW 2992 and optimal dosing schedule in advanced solid tumors.

A 14 days on/14 days off, once daily dosing regimen, escalating from $10 \mathrm{mg}$ to $100 \mathrm{mg}$ was investigated by Eskens et al. ${ }^{36}$ Thirty-eight patients (performance status [PS]: 0-2) with tumors historically considered to express EGFR and/or HER2, refractory to standard therapy were enrolled. This included three patients with NSCLC. Dose limiting toxicity (DLT) included rash, diarrhea, and elevated ALT, and the subsequent recommended dose for future Phase II studies using this schedule was $70 \mathrm{mg}$ per day. The median number of cycles delivered was 6 (range 5-9). No CR (complete response) or PR (partial response) to treatment was documented yet seven patients achieved SD lasting $\geq$ four cycles.

Two Phase I studies assessed continuous daily dosing with afatinib. Both trials recruited patients with malignancies associated with overexpression of EGFR and or HER2. In the UK study, 53 patients, including 16 with NSCLC were treated with escalating doses of afatinib. ${ }^{41}$ DLTs at the $50 \mathrm{mg} /$ day dose included common toxicity criteria (CTC) grade 3 pneumonitis (reversible) and rash and this was subsequently recommended as the Phase II dose. Thirty-four of the patients were evaluable for response. Five achieved a PR; of note, four of these were patients with NSCLC (although in one case the PR was unconfirmed). Of the three confirmed responses, the PR was durable, with patients remaining on treatment for between 18 and 34 months. Furthermore, two of the confirmed PR patients were female ex-smokers, and their tumors were found later to have activating in-frame deletion mutations in exon 19 of the EGFR domain. A further 22 patients were recruited by Agus et al. ${ }^{40}$ At the $60 \mathrm{mg}$ dose, two-thirds of patients treated developed diarrhea, which was considered the DLT. In view of this, the cohort receiving the dose level below (40 mg) was expanded to include a total of 18 patients. Drug pharmacokinetics at interim analysis (nine patients) were comparable to previous trials. No response data are available.

Lewis et al also recommended the $40 \mathrm{mg}$ dose level in a confirmatory Phase I dose escalation study involving 43 patients with advanced refractory disease. ${ }^{42}$ Patients received afatinib on a 21 days on/7 days off schedule, with dose levels between 10 and $65 \mathrm{mg} /$ day. In the expanded $55 \mathrm{mg}$ dose cohort, seven out of 20 patients experienced a DLT. Only two patients enrolled had NSCLC. No PR was detected in the 35 evaluable patients, however 15 (43\%) achieved SD and remained on treatment for more than 3 months. Preliminary PK data concur with previous studies.

Combining afatinib with chemotherapeutic agents has also been assessed in the setting of refractory malignancy. Specifically the safety and efficacy of afatinib in combination with cetuximab has also recently been investigated in patients with advanced NSCLC and acquired resistance to EGFR-TKIs. ${ }^{43}$ Acquired resistance was defined by previous EGFR-TKI therapy and the presence of an EGFR sensitizing mutation and/or objective response to this EGFR-TKI treatment, followed by systemic progression of disease whilst receiving EGFR-TKI treatment within the last 30 days, and no intervening systemic therapy between the cessation of EGFRTKI and initiation of new therapy. ${ }^{44}$ This unique patient cohort 
had previously been on treatment with either gefitinib or erlotinib for a median time of 2.4 years prior to trial entry. Patients received $40 \mathrm{mg}$ afatinib daily and an escalating dose of bi-weekly cetuximab at either 250 or $500 \mathrm{mg} / \mathrm{m}^{2}$. Patients established on the maximum pre-defined doses of afatinib (40 mg daily) and cetuximab $\left(500 \mathrm{mg} / \mathrm{m}^{2}\right)$ were assessed for response. Disease control was achieved in all of the 22 evaluable patients. Confirmed PR was validated in eight of the 22 patients (PR: 36\%, CI: 0.17-0.59). Furthermore of those patients harboring the T790M mutation $(n=13)$, four PRs (29\%) were recorded.

Afatinib has also been investigated in combination with weekly paclitaxel, 3-weekly docetaxel, vinorelbine, cisplatinpaclitaxel, and cisplatin-5FU in advanced solid malignancies. These studies have demonstrated tolerable toxicity and some evidence of clinical efficacy. ${ }^{45-48}$ Phase I combination studies are summarized in Table 1.

\section{Phase II/III clinical studies in NSCLC}

The LUX trials are a program of clinical studies investigating afatinib in a range of solid tumor types, with a particular focus on NSCLC.

The LUX-Lung 1 trial was a multicenter Phase IIb/III study comparing afatinib $50 \mathrm{mg}$ orally once daily plus BSC to placebo plus BSC in patients with advanced NSCLC (adenocarcinoma only). Patients who had received prior chemotherapy and at least 12 weeks of erlotinib or gefitinib with a PS $0-1$ were deemed eligible. ${ }^{49}$ Five hundred and eighty-five patients were recruited and randomized $2: 1$ in favor of the study drug. More than $50 \%$ of patients were of Asian origin and approximately two-thirds were never smokers. The primary endpoint of the trial was OS, with secondary endpoints of PFS, RR and QOL.

The median duration of therapy was 10 months and toxicity was manageable with supportive treatments or dose reduction. Side effects reported included diarrhea (all CTC grades in 87\%, CTC grade 3 in 17\%) and rash (all CTC grades in 79\%, CTC grade 3 in 14\%). An independently confirmed overall response rate (ORR) of just 7\% was reported; however, a significantly higher disease control rate (SD or PR) for afatinib compared to placebo (58\% vs $19 \% ; P<0.0001$ ) was demonstrated at 8 weeks. Furthermore a significant improvement in the secondary endpoint of PFS in favor of afatinib was reported (3.3 vs 1.1 months; hazard ratio [HR]: $0.38 ; P<0.0001$ ).

Importantly, in the management of advanced lung cancer, significant improvements in symptoms of cough, dyspnea, and pain were observed in the afatinib group (11\%-20\%). All patient outcome scores were estimated from the European Organization for Research and Treatment of Cancer (EORTC) Quality of Life Questionnaire (QLQ)-LC13 and EORTC QLQ-C30. Improvement was defined as symptom scores falling by 10 points below baseline at any time during the study. EORTC cough, dyspnea, and pain endpoints were as pre-specified in the trial protocol.

There was however no improvement in OS between the two arms (10.7 vs 11.9 months; HR: 1.08, 95\% CI: 0.86-1.35;

Table I Phase I trials combining afatinib with other anti-cancer agents

\begin{tabular}{|c|c|c|c|c|c|}
\hline Study agents & Patients & n (NSCLC) & DLTs & $\begin{array}{l}\text { Phase II } \\
\text { afatinib dose }\end{array}$ & Efficacy results \\
\hline $\begin{array}{l}\text { Afatinib } 40 \mathrm{mg} \text { daily + } \\
\text { cetuximab } 250-500 \mathrm{mg} / \mathrm{m}^{2} \\
\text { bi-weekly }{ }^{43}\end{array}$ & $\begin{array}{l}\text { NSCLC with acquired } \\
\text { resistance to EGFR-TKI }\end{array}$ & 26 & Nil & & $\begin{array}{l}\text { In } 22 \text { patients receiving } \\
\text { afatinib } 40 \mathrm{mg}+\text { cetuximab } \\
500 \mathrm{mg} / \mathrm{m}^{2} \text {; SD 22/22 PR 8/22 }\end{array}$ \\
\hline $\begin{array}{l}\text { Afatinib } 20-50 \mathrm{mg} \\
\text { daily + paclitaxel } 80 \mathrm{mg} / \mathrm{m}^{2} \\
\text { DI, } 8,15 \text { q2845 }\end{array}$ & $\begin{array}{l}\text { Advanced solid tumors } \\
\text { expressing EGFR. PS 0-I }\end{array}$ & 16 & Mucositis, fatigue & $40 \mathrm{mg}$ & $\begin{array}{l}\mathrm{PR}=6(3 \mathrm{NSCLC}) \\
\mathrm{SD}=8\end{array}$ \\
\hline $\begin{array}{l}\text { Afatinib } 10-160 \mathrm{mg} \text { D2-4+ } \\
\text { docetaxel } 75 \mathrm{mg} / \mathrm{m}^{2} \mathrm{q} 21^{46}\end{array}$ & Advanced solid tumors & 40 & $\begin{array}{l}\text { Neutropenia, nausea, } \\
\text { diarrhea }\end{array}$ & $90 \mathrm{mg}$ & $\begin{array}{l}\mathrm{PR}=4 \\
\mathrm{CR}=1 \\
\mathrm{SD}=10\end{array}$ \\
\hline $\begin{array}{l}\text { Afatinib } 20-50 \mathrm{mg} \text { daily + } \\
\text { vinorelbine } \\
25 \mathrm{mg} / \mathrm{m}^{2} \mathrm{DI}, 8,15,22 \\
\mathrm{q} 28^{47}\end{array}$ & $\begin{array}{l}\text { Advanced solid } \\
\text { tumors, PS 0-I }\end{array}$ & $15(4)$ & $\begin{array}{l}\text { Mucositis, febrile } \\
\text { neutropenia, diarrhea }\end{array}$ & $40 \mathrm{mg}$ & $\mathrm{n} / \mathrm{a}$ \\
\hline $\begin{array}{l}\text { Afatinib } 20-50 \mathrm{mg} \text { daily + A: } \\
\text { cisplatin/paclitaxel q2I B: } \\
\text { cisplatin/5FU q2 }{ }^{48}\end{array}$ & $\begin{array}{l}\text { Advanced solid } \\
\text { tumors }\end{array}$ & 47 & $\begin{array}{l}\text { Neutropenic sepsis, } \\
\text { elevated AST/ALT, } \\
\text { asthenia, mucositis, } \\
\text { diarrhea }\end{array}$ & $\begin{array}{l}\text { A; } 40 \mathrm{mg} \\
\mathrm{B} ; 30 \mathrm{mg}\end{array}$ & $\begin{array}{l}A ; P R=4 \\
S D=I I \\
B ; C R=I \\
P R=3 \\
S D=8\end{array}$ \\
\hline
\end{tabular}

Abbreviations: DLT, dose-limiting toxicity; SD, stable disease; PR, partial response; CR, complete response; PS, performance status. 
$P=0.74)$. As patients frequently went on to receive further systemic anti-cancer therapies when disease progression was confirmed within the trial, it is possible that further therapeutic intervention may have confounded OS results.

The selection criterion for the LUX-1 trial was such that a high proportion of EGFR mutation-positive patients were likely to be included. Sub-group analysis identifying this group as those achieving CR/PR on prior EGFR-TKI therapy and/or $\geq 48$ weeks on treatment with EGFR-TKI (67\% of patients) reported a PFS and OS for those receiving placebo of 1 month and 11.2 months, respectively. Those receiving afatinib however had a significantly prolonged PFS of 4.4 months (HR: $0.28,95 \%$ CI: $0.210-0.362$ ). OS was 11.8 months (HR: $0.90,95 \%$ CI: 0.686-1.176), suggesting only a possible trend towards improved survival. ${ }^{50}$

It should be noted that the relatively high survival in both arms of this study despite the heavily pre-treated nature of the study population, likely reflects the fact that the majority of patients were of good performance status $(0-1)$ and had received benefit from first generation EGFR TKI prior to entry into the trial, as it is recognized that the EGFR mutation population tends to have better survival generally.

The Phase II LUX-Lung 2 trial evaluated patients with EGFR mutation-positive stage IIIb/IV NSCLC (adenocarcinoma). ${ }^{51}$ Patients of PS 0-2 from Taiwan and the US received afatinib, 40 or $50 \mathrm{mg}$ orally once daily until disease progression. In this two stage trial design, only patients having progressed on standard chemotherapy were recruited initially. At a planned interim analysis, 21 of the first 38 patients had a confirmed response after 28 days of treatment and therefore the trial was expanded to also include chemotherapy-naïve patients. One hundred and twenty-nine patients were recruited in total. The ORR, the primary endpoint of the study, was $57 \%$. Disease-control was confirmed in $86 \%$ of patients. Median PFS and OS were 14 and 24 months, respectively. Afatinib was generally well tolerated with CTC grade 3 diarrhea and rash being the most serious toxicities reported.

The majority of patients had del19 or L858R mutations $(82 \%)$ and clinical outcomes were similar for both these groups. In a subgroup analysis of 23 (17.8\%) patients who had less common EGFR mutations, an ORR of $70 \%$ and disease stabilization rate of $90 \%$ was reported, suggesting that this group is also sensitive to afatinib. Patients with exon 20 insertions had shorter PFS and OS compared to those with other less common mutations (13.7 vs 2.8 months and 22 vs 9.2 months, respectively). The one patient with an L858R/ T790M mutation did not respond. ${ }^{52}$
A further Japanese Phase II study recently reported encouraging response rates to afatinib therapy in patients with heavily pre-treated stage IIIb/IV NSCLC.$^{53}$ For inclusion, patients were PS 0-1 and could have received 1-2 lines of prior chemotherapy in addition to receiving more than 12 weeks of EGFR-TKI therapy. The primary endpoint was ORR. Sixty-two patients, of whom $73 \%$ were EGFR mutation positive received afatinib $50 \mathrm{mg}$ daily. Disease control for more than 8 weeks was confirmed in $67 \%$, with $8.2 \%$ achieving a PR. The median PFS was 4.6 months. Overall $82 \%$ of these patients met the definition of "acquired EGFR-TKI resistance" and in this subset a 5.9\% PR was demonstrated, with a disease control rate (DCR) of $69 \%$ and median PFS of 4.4 months. Afatinib was well tolerated and demonstrated possible efficacy in increasingly resistant disease.

Other global clinical trials currently evaluating afatinib's role in the management of advanced NSCLC are listed in Table 2.

\section{Safety and tolerability of afatinib}

The clinical studies to date indicate that afatinib is well tolerated with most adverse events (AEs) reported as mild-to-moderate (NCI-CTC grade 1 or 2). Gastrointestinal toxicity (most commonly diarrhea, but also nausea, vomiting, and mucositis) and fatigue were observed to be similar to those seen with other TKIs and were generally self-limiting or adequately controlled by appropriate medication. Specifically, diarrhea was reported in $87 \%$ and $95 \%$ of patients in the LUX-Lung 1 and 2 trials. ${ }^{49,51}$ Cutaneous toxicity including rash, dry skin, acne, and folliculitis, was common but again generally mild and self-limiting. Rash/ acne was observed in $78 \%$ and $91 \%$ of patients in the LUX-Lung 1 and 2 trials, respectively; however, grade 3 skin toxicity only affected fewer than $20 \%$ of patients. ${ }^{49,51}$ Occasional liver enzyme elevation was noted and appeared to be dose-dependent. ${ }^{36}$ DLTs in the Phase I trials included grade 3 rash, diarrhea, and elevation of alanine transaminase (ALT).

Because of the known expression of HER2 on cardiac myocytes, normal cardiac function was required for inclusion in the Phase I studies and was subsequently monitored throughout; in the first Phase I trial two patients had asymptomatic reduction in $\mathrm{LVEF}^{36}$ but this was not demonstrated in subsequent trials and no causal link has been established. Additionally, no drug-induced QTc prolongation has been observed compared to baseline in a recent Phase II open-label study of 60 patients (35\% NSCLC) treated with afatinib $50 \mathrm{mg}$ daily. ${ }^{54}$ Similarly, patients with pre-existing interstitial lung disease were excluded from these trials and only one case of pneumonitis which was reversible was reported. 
Table 2 Summary of current $\mathrm{NCl}$ trials evaluating the role of afatinib in NSCLC ${ }^{32}$

\begin{tabular}{|c|c|c|c|c|c|c|}
\hline Trial & Agents & Location & Design & Participants/schedule & $I^{\circ}$ endpoint & $2^{\circ}$ endpoint \\
\hline $\begin{array}{l}\text { LUX-Lung } 3 \\
\text { NCT00949650 }\end{array}$ & $\begin{array}{l}\text { Afatinib vs cisplatin/pemetrexed } \\
\text { as Ist line treatment for lung } \\
\text { adenocarcinoma with EGFR } \\
\text { mutation }\end{array}$ & $\begin{array}{l}\text { EU, USA, } \\
\text { Canada }\end{array}$ & $\begin{array}{l}\text { Randomised } \\
\text { Phase III }\end{array}$ & $\begin{array}{l}\text { Stage IIIB/IV adenocarcinoma, } \\
\text { EGFR mutation, } \\
\text { chemotherapy and EGFR TKI } \\
\text { naïve }\end{array}$ & PFS & $\begin{array}{l}\text { RR, OS, } \\
\text { HRQOL, safety }\end{array}$ \\
\hline $\begin{array}{l}\text { LUX-Lung } 5 \\
\text { NCT0I085I36 }\end{array}$ & $\begin{array}{l}\text { Afatinib + weekly paclitaxel } \\
\text { vs investigator's choice } \\
\text { chemotherapy, following } \\
\text { progression on afatinib }\end{array}$ & Global & $\begin{array}{l}\text { Randomised } \\
\text { Phase III }\end{array}$ & $\begin{array}{l}\text { Stage IIIB/IV NSCLC, failed } \\
\text { EGFR TKI and } \geq I \text { line } \\
\text { of chemotherapy }\end{array}$ & OS & $\begin{array}{l}\text { RR, PFS, } \\
\text { HRQOL, safety }\end{array}$ \\
\hline $\begin{array}{l}\text { LUX-Lung } 6 \\
\text { NCT0II } 21393\end{array}$ & $\begin{array}{l}\text { Afatinib vs cisplatin/gemcitabine } \\
\text { as Ist line treatment for lung } \\
\text { adenocarcinoma with EGFR } \\
\text { mutation }\end{array}$ & $\begin{array}{l}\text { China, } \\
\text { Korea }\end{array}$ & $\begin{array}{l}\text { Randomised } \\
\text { Phase III }\end{array}$ & $\begin{array}{l}\text { Stage IIIB/IV, } \\
\text { adenocarcinoma, EGFR } \\
\text { mutation, chemotherapy } \\
\text { and EGFR TKI naïve }\end{array}$ & PFS & $\begin{array}{l}\text { RR, OS, } \\
\text { HRQOL, safety }\end{array}$ \\
\hline NCT0I003899 & $\begin{array}{l}\text { Afatinib as } 3 r \text { line treatment } \\
\text { for lung adenocarcinoma with } \\
\text { wild-type EGFR }\end{array}$ & Korea & Phase II & $\begin{array}{l}\text { Stage IIIB/IV, } \\
\text { adenocarcinoma, wild-type } \\
\text { EGFR, progressed on } \geq 2 \\
\text { prior chemotherapies }\end{array}$ & RR & $\begin{array}{l}\text { PFS, safety } \\
\text { Exploratory } \\
\text { biomarkers }\end{array}$ \\
\hline NCT00993499 & $\begin{array}{l}\text { Afatinib + sirolimus in NSCLC } \\
\text { with EGFR mutation and/or } \\
\text { prior response to erlotinib }\end{array}$ & Spain & Phase I & $\begin{array}{l}\text { Stage IIIB/IV NSCLC } \\
\text { with EGFR mutation and/or } \\
\text { previous response to } \\
\text { erlotinib, failed } \geq \text { I prior } \\
\text { chemotherapies }\end{array}$ & $\begin{array}{l}\text { MTD and } \\
\text { Phase II dose }\end{array}$ & $\begin{array}{l}\text { Safety, PK } \\
\text { analysis, RR }\end{array}$ \\
\hline NCTOII 56545 & $\begin{array}{l}\text { Afatinib + simvastatin vs afatinib } \\
\text { alone for non-adenocarcinoma } \\
\text { NSCLC }\end{array}$ & Korea & $\begin{array}{l}\text { Randomised } \\
\text { Phase II }\end{array}$ & $\begin{array}{l}\text { Stage IIIB/IV non- } \\
\text { adenomatous NSCLC, } \\
\text { progressed } \geq \text { I prior } \\
\text { chemotherapies }\end{array}$ & $\mathrm{RR}$ & $\begin{array}{l}\text { PFS, OS, safety, } \\
\text { biomarker } \\
\text { analysis }\end{array}$ \\
\hline
\end{tabular}

Abbreviations: PFS, progression-free survival; OS, overall survival; RR, response rate; HRQOL, health related quality of life; MTD, maximum tolerated dose.

\section{Patient perspectives}

Despite afatinib's relatively early stage in drug development, trials demonstrate activity in advanced NSCLC, especially for those patients likely to be harboring sensitizing EGFR mutations. The LUX-Lung 1 trial demonstrated significant improvements in QOL and PFS in patients with advanced NSCLC though this has not yet translated into improved OS. Maintaining QOL and improving respiratory symptoms is the cornerstone of palliative treatment in advanced disease and therefore afatinib may represent a novel treatment strategy in this setting with a clear underlying rationale at the molecular level.

Targeted systemic therapies in general are perceived as less toxic than standard chemotherapy and therefore more acceptable. Furthermore as an oral agent, compliance with drug treatment is likely to be high. Afatinib AEs are generally predictable and there is significant overlap in side effects and their management with the first-generation EGFR-TKIs. In the LUX-Lung 2 trial however, $42.9 \%$ patients required a dose reduction to $40 \mathrm{mg}, 11 \%$ to $30 \mathrm{mg}$ and one discontinued due to severe AEs. These data suggest regular toxicity assessment and aggressive management of AEs is required for patients to ensure maximal benefit from therapy.
In the LUX-Lung 1 trial, the majority of patients had good performance status (PS 0-1), and therefore may not be truly representative of the population of advanced lung cancer patients where third-line therapy is frequently considered inappropriate. Currently there are no FDA-approved therapies for patients with advanced NSCLC who progress following chemotherapy and become refractory to firstgeneration EGFR-TKIs. Afatinib may provide a therapeutic option for this selected population. As more trials report, it will become clear which patient subgroups will benefit most and the optimal timing for afatinib therapy in the evolving treatment algorithm for advanced NSCLC.

Afatinib is currently unlicensed; however, a number of registration trials are ongoing. Outside clinical trials, afatinib is available as part of an expanded access scheme, allowing compassionate use of the drug in patients of PS 0-2, having previously received both a standard platinum-containing chemotherapy regimen and a first generation EGFR-TKI.

\section{Conclusion}

Advanced NSCLC is an aggressive disease with limited therapeutic options. Recent advances however have highlighted the importance of considering tumor histology in the 
treatment decision-making algorithm. In the first-line setting, not only does the adenocarcinoma subgroup have improved OS with pemetrexed-based doublet chemotherapy, but those with proven $E G F R$ mutations have superior outcomes with EGFR-TKI therapy. Targeting EGFR mutant positive patients has been a paradigm shift in patient management improving response and PFS using EGFR-TKIs compared to standard chemotherapy. EGFR testing has now become routine for non-squamous advanced NSCLC. Despite these successes, a proportion of patients remain refractory to therapy, and those that do respond, ultimately develop resistance and disease relapse. For these patients, therapeutic options to date, especially in the third-line setting offer little additional benefit above BSC.

Drug development to overcome these mechanisms of resistance has resulted in the development of a number of novel agents. Afatinib as an irreversible dual kinase inhibitor presents a potential molecular solution which is currently being evaluated clinically.

Pre-clinical/early phase trials provide evidence of disease activity and tolerability (with toxicity due to inhibition of wild-type $E G F R$ reported as mild-to-moderate and similar to first-generation EGFR-TKIs), though data as yet is limited. The LUX-Lung trials suggest that afatinib may be able to overcome acquired resistance to reversible EGFR-TKIs and that it may be potentially as effective as erlotinib or gefitinib as first-line treatment for patients with EGFR mutation. For selected patients, afatinib offers symptomatic improvement and prolonged PFS, though this has not yet translated into improved OS.

For those patients considered fit enough for third-line therapy, especially those with proven EGFR sensitizing mutations, afatinib as part of an expanded access scheme is now available. The drug however remains unlicensed. Future studies assessing the combination of afatinib plus chemotherapy or afatinib plus additional targeted therapy may increase efficacy. The portfolio of LUX trials will determine the optimal timing for treatment with afatinib in advanced NSCLC and identify those who will benefit most.

In this evolving era of personalized medicine, overcoming resistance using more sophisticated targeted agents will hopefully lead to eventual significant improvements in not only quality of life and PFS but also OS in advanced NSCLC.

\section{Disclosure}

The authors report no conflicts of interest in this work.

\section{References}

1. Baggstrom MQ, Stinchcombe TE, Fried DB, Poole C, Hensing TA, Socinski MA. Third-generation chemotherapy agents in the treatment of advanced non-small cell lung cancer: a meta-analysis. $J$ Thorac Oncol. 2007;2(9):845-853.

2. Rosell R, Gatzemeier U, Betticher DC, et al. Phase III randomised trial comparing paclitaxel/carboplatin with paclitaxel/cisplatin in patients with advanced non-small-cell lung cancer: a cooperative multinational trial. Ann Oncol. 2002;13(10):1539-1549.

3. Schiller JH, Harrington D, Belani CP, et al. Comparison of four chemotherapy regimens for advanced non-small-cell lung cancer. $N$ Engl J Med. 2002;346(2):92-98.

4. Zatloukal P, Petruzelka L, Zemanova M, et al. Gemcitabine plus cisplatin vs gemcitabine plus carboplatin in stage IIIb and IV non-small cell lung cancer: a phase III randomized trial. Lung Cancer. 2003; 41(3):321-331.

5. Scagliotti GV, Parikh P, von Pawel J, et al. Phase III study comparing cisplatin plus gemcitabine with cisplatin plus pemetrexed in chemotherapy-naive patients with advanced-stage non-small-cell lung cancer. J Clin Oncol. 2008;26(21):3543-3551.

6. Sandler A, Gray R, Perry MC, et al. Paclitaxel-carboplatin alone or with bevacizumab for non-small-cell lung cancer. $N$ Engl J Med. 2006; 355(24):2542-2550.

7. Pirker R, Pereira JR, Szczesna A, et al. Cetuximab plus chemotherapy in patients with advanced non-small-cell lung cancer (FLEX): an openlabel randomised phase III trial. Lancet. 2009;373(9674):1525-1531.

8. Ciuleanu T, Brodowicz T, Zielinski C, et al. Maintenance pemetrexed plus best supportive care versus placebo plus best supportive care for non-small-cell lung cancer: a randomised, double-blind, phase 3 study. Lancet. 2009;374(9699):1432-1440.

9. Cataldo VD, Gibbons DL, Perez-Soler R, Quintas-Cardama A. Treatment of non-small-cell lung cancer with erlotinib or gefitinib. N Engl J Med.;364(10):947-955.

10. Mok TS, Wu YL, Thongprasert S, et al. Gefitinib or carboplatinpaclitaxel in pulmonary adenocarcinoma. N Engl J Med. 2009;361(10): 947-957.

11. Kobayashi K, Inoue A, Maemondo M, et al. First-line gefitinib versus first-line chemotherapy by carboplatin (CBDCA) plus paclitaxel (TXL) in non-small cell lung cancer (NSCLC) patients (pts) with EGFR mutations: A phase III study (002) by North East Japan Gefitinib Study Group [abstract]. J Clin Oncol. 2009;27(15S):8016.

12. Lee JS, Park K, Kim SW, et al. A randomized phase III study of gefitinib (IRESSATM) versus standard chemotherapy (gemcitabine plus cisplatin) as a first-line treatment for never-smokers with advanced or metastatic adenocarcinoma of the lung [abstract]. Proceedings of the 13th World Conference on Lung Cancer, July 31-August 4, 2009; San Francisco, CA. (Abstract PRS.4).

13. Mitsudomi T, Morita S, Yatabe Y, et al. Gefitinib versus cisplatin plus docetaxel in patients with non-small-cell lung cancer harbouring mutations of the epidermal growth factor receptor (WJTOG3405): an open label, randomised phase 3 trial. Lancet Oncol. 2010;11(2): $121-128$.

14. Zhou C, Wu Y, Chen G, et al. Efficacy results from the randomised phase III OPTIMAL (CTONG 0802) study comparing first-line erlotinib versus carboplatin plus gemcitabine, in Chinese advanced non-small cell lung cancer (NSCLC) patients (pts) with EGFR activating mutations [abstract]. Ann Oncol. 2010;21(Suppl 8):LBA13.

15. Shepherd FA, Dancey J, Ramlau R, et al. Prospective randomized trial of docetaxel versus best supportive care in patients with non-small-cell lung cancer previously treated with platinum-based chemotherapy. J Clin Oncol. 2000;18(10):2095-2103.

16. Hanna N, Shepherd FA, Fossella FV, et al. Randomized phase III trial of pemetrexed versus docetaxel in patients with non-small-cell lung cancer previously treated with chemotherapy. J Clin Oncol. 2004;22(9): $1589-1597$. 
17. Shepherd FA, Rodrigues Pereira J, Ciuleanu T, et al. Erlotinib in previously treated non-small-cell lung cancer. $N$ Engl J Med. 2005; 353(2):123-132.

18. Thatcher N, Chang A, Parikh P, et al. Gefitinib plus best supportive care in previously treated patients with refractory advanced nonsmall-cell lung cancer: results from a randomised, placebo-controlled, multicentre study (Iressa Survival Evaluation in Lung Cancer). Lancet. 2005;366(9496):1527-1537.

19. Kim ES, Hirsh V, Mok T, et al. Gefitinib versus docetaxel in previously treated non-small-cell lung cancer (INTEREST): a randomised phase III trial. Lancet. 2008;372(9652):1809-1818.

20. Janne PA, Engelman JA, Johnson BE. Epidermal growth factor receptor mutations in non-small-cell lung cancer: implications for treatment and tumor biology. J Clin Oncol. 2005;23(14):3227-3234.

21. Pao W, Miller VA. Epidermal growth factor receptor mutations, smallmolecule kinase inhibitors, and non-small-cell lung cancer: current knowledge and future directions. J Clin Oncol. 2005;23(11): 2556-2568.

22. Rosell R, Moran T, Queralt C, et al. Screening for epidermal growth factor receptor mutations in lung cancer. $N$ Engl $J$ Med. 2009;361(10):958-967.

23. Forbes S, Clements J, Dawson E, et al. Cosmic 2005. Br J Cancer. 2006;94(2):318-322.

24. Massarelli E, Varella-Garcia M, Tang X, et al. KRAS mutation is an important predictor of resistance to therapy with epidermal growth factor receptor tyrosine kinase inhibitors in non-small-cell lung cancer. Clin Cancer Res. 2007;13(10):2890-2896.

25. Zhu CQ, da Cunha Santos G, Ding K, et al. Role of KRAS and EGFR as biomarkers of response to erlotinib in National Cancer Institute of Canada Clinical Trials Group Study BR.21. J Clin Oncol. 2008;26(26):4268-4275.

26. Giaccone G, Wang Y. Strategies for overcoming resistance to EGFR family tyrosine kinase inhibitors. Cancer Treat Rev. 2011;37(6): 456-464.

27. Paz-Ares L, Soulieres D, Melezinek I, et al. Clinical outcomes in nonsmall-cell lung cancer patients with EGFR mutations: pooled analysis. J Cell Mol Med. 2010;14(1-2):51-69.

28. Maheswaran S, Sequist LV, Nagrath S, et al. Detection of mutations in EGFR in circulating lung-cancer cells. $N$ Engl $J$ Med. 2008;359(4):366-377.

29. Pao W, Miller VA, Politi KA, et al. Acquired resistance of lung adenocarcinomas to gefitinib or erlotinib is associated with a second mutation in the EGFR kinase domain. PLoS Med. 2005;2(3):e73.

30. Bean J, Brennan C, Shih JY, et al. MET amplification occurs with or without T790M mutations in EGFR mutant lung tumors with acquired resistance to gefitinib or erlotinib. Proc Natl Acad Sci U SA. 2007;104(52):20932-20937.

31. Engelman JA, Zejnullahu K, Mitsudomi T, et al. MET amplification leads to gefitinib resistance in lung cancer by activating ERBB3 signaling. Science. 2007;316(5827):1039-1043.

32. Available from: http://www.clinicaltrials.gov.

33. Sequist LV, Besse B, Lynch TJ, et al. Neratinib, an irreversible panErbB receptor tyrosine kinase inhibitor: results of a phase II trial in patients with advanced non-small-cell lung cancer. J Clin Oncol. 2010;28(18):3076-3083.

34. Janne PA, von Pawel J, Cohen RB, et al. Multicenter, randomized, phase II trial of CI-1033, an irreversible pan-ERBB inhibitor, for previously treated advanced non-small-cell lung cancer. J Clin Oncol. 2007;25(25):3936-3944.

35. Janne P, Reckamp K, Koczywas M, et al. Efficacy and safety of PF-00299804 (PF299) in patients (pt) with advanced NSCLC after failure of at least one prior chemotherapy regimen and prior treatment with erlotinib (E): A two-arm, phase II trial [abstract]. J Clin Oncol. 2009;27(15S):8063.

36. Eskens FA, Mom CH, Planting AS, et al. A phase I dose escalation study of BIBW 2992, an irreversible dual inhibitor of epidermal growth factor receptor 1 (EGFR) and 2 (HER2) tyrosine kinase in a 2-week on, 2-week off schedule in patients with advanced solid tumours. $\mathrm{Br} \mathrm{J}$ Cancer. 2008;98(1):80-85.
37. Li D, Ambrogio L, Shimamura T, et al. BIBW2992, an irreversible EGFR/HER2 inhibitor highly effective in preclinical lung cancer models. Oncogene. 2008;27(34):4702-4711.

38. Solca F, Baum A, Guth B, et al. BIBW 2992, an irreversible dual EGFR/ HER2 receptor tyrosine kinase inhibitor for cancer therapy [abstract]. Proceedings, AACR-NCI-EORTC International Conference on Molecular Targets and Cancer Therapeutics. Philadelphia, PA. November 14-18, 2005:118 (Abstract A244).

39. Stopfer P, Narjes H, Gaschler-Markefski B, Gansser D, Shahidi M. Pharmacokinetics (PK) of [14C]-BIBW 2992 after administration of a single dose of $15 \mathrm{mg}$ [14C]-BIBW 2992 oral solution in healthy male volunteers [abstract]. J Clin Oncol. 2008;26(Suppl):14607.

40. Agus DB, Terlizzi E, Stopfer P, Amelsberg A, Gordon MS. A phase I dose escalation study of BIBW 2992, an irreversible dual EGFR/ HER2 receptor tyrosine kinase inhibitor, in a continuous schedule in patients with advanced solid tumours [abstract]. J Clin Oncol. 2006; 24(18S):2074.

41. Yap TA, Vidal L, Adam J, et al. Phase I trial of the irreversible EGFR and HER2 kinase inhibitor BIBW 2992 in patients with advanced solid tumors. J Clin Oncol. 2010;28(25):3965-3972.

42. Lewis N, Marshall J, Amelsberg A, et al. A phase I dose escalation study of BIBW 2992, an irreversible dual EGFR/HER2 receptor tyrosine kinase inhibitor, in a 3 week on 1 week off schedule in patients with advanced solid tumours [abstract]. J Clin Oncol. 2006;24 (18S):3091.

43. Janjigian Y, Groen H, Horn L, et al. Activity and tolerability of afatinib (BIBW 2992) and cetuximab in NSCLC patients with acquired resistance to erlotinib or gefitinib [abstract]. J Clin Oncol. 2011; 29(15S):7525.

44. Jackman D, Pao W, Riely GJ, et al. Clinical definition of acquired resistance to epidermal growth factor receptor tyrosine kinase inhibitors in non-small-cell lung cancer. J Clin Oncol. 2009;28(2):357-360.

45. Ang J, Mikropoulos C, Stavridi F, et al. A phase I study of daily BIBW 2992, an irreversible EGFR/HER-2 dual kinase inhibitor, in combination with weekly paclitaxel [abstract]. J Clin Oncol. 2009; 27(15S): e14541.

46. Awada A, Dumez H, Wolter P, et al. A phase I dose finding study of the 3-day administration of BIBW 2992, an irreversible dual EGFR/ HER-2 inhibitor, in combination with three-weekly docetaxel in patients with advanced solid tumors [abstract]. J Clin Oncol. 2009; 27(15S):e3556.

47. Bahleda R, Soria J, Berge Y, et al. Phase I trial assessing safety and pharmacokinetics of afatinib (BIBW 2992) with intravenous weekly vinorelbine in advanced solid tumors [abstract]. J Clin Oncol. 2011;29(15S):2585.

48. Vermorken J, Machiels J, Rottey S, Thurm H, Pelling K, Lahogue A. Phase Ib study evaluating the combination of BIBW 2992 with two different standard chemotherapy regimens, cisplatin/paclitaxel (PT) and cisplatin/5-FU (PF), in patients with advanced solid tumors [abstract]. J Clin Oncol. 2010;28 (Suppl):e13521.

49. Miller VA, Hirsh V, Cadranel J, et al. Phase IIb/III double-blind randomized trial of BIBW 2992, an irreversible inhibitor of EGFR/ HER1 and HER2 + best supportive care (BSC) versus placebo + BSC in patients with NSCLC failing $1-2$ lines of chemotherapy and erlotinib or gefitinib (LUX-Lung 1) [abstract]. European Society of Medical Oncology (ESMO) Congress, Milan, Italy, October 2010. Ann Oncol. 2010;21(Suppl 8):viii1.

50. Miller VA. Subgroup analysis of LUX-Lung 1; A randomised phase III trial of Afatinib (BIBW 2992) + best supportive care (BSC) versus placebo + BSC in patients with NSCLC failing 1-2 lines of chemotherapy and erlotinib or gefitinib. Oral presentation at Chicago Multidisciplinary Symposium in Thoracic Oncology. Chicago, IL, December, 2010.

51. Yang G, Shih J, Su W, et al. A phase II study of BIBW 2992 in patients with adenocarcinoma of the lung and activating EGFR/ HER1 mutations (LUX-LUNG 2) [abstract]. J Clin Oncol. 2010; 28(15s):7521. 
52. Shih J, Yu C, Su W, et al. Activity of BIBW 2992, an irreversible EGFR/ HER1 and HER2 TKI, in lung adenocarcinoma patients harbouring less common EGFR mutations [abstract]. Annals Oncol. 2010;21(Suppl 8): viii122-viii161:415P.

53. Yamamoto N, Katakami N, Atagi S, et al. A phase II trial of afatinib (BIBW 2992) in patients (pts) with advanced non-small cell lung cancer previously treated with erlotinib (E) or gefitinib (G) [abstract]. J Clin Oncol. 2011;29(15S):7524.
54. Kristeleit H, Puglisi M, Middleton G, et al. Phase II, open-label trial to assess the effect of continuous oral afatinib (BIBW 2992) at a daily dose of $50 \mathrm{mg}$ on QTc, pharmacokinetics, and efficacy in relapsed or refractory solid tumors including brain metastases and glioblastoma that is not amenable to other therapy [abstract]. J Clin Oncol. 2011;29(15S):2613.

\section{Publish your work in this journal}

Lung Cancer: Targets and Therapy is an international, peer-reviewed, open access journal focusing on lung cancer research, identification of therapeutic targets and the optimal use of preventative and integrated treatment interventions to achieve improved outcomes, enhanced survival and quality of life for the cancer patient. Specific topics covered in the journal include:

\section{Dovepress}

Epidemiology, detection and screening; Cellular research and biomarkers; Identification of biotargets and agents with novel mechanisms of action; Optimal clinical use of existing anticancer agents, including combination therapies; Radiation and surgery; Palliative care; Patient adherence, quality of life, satisfaction; Health economic evaluations.

Submit your manuscript here: http://www.dovepress.com/lung-cancer-targets--therapy-journal 